\title{
Spontaneous CSF Rhinorrhea as Clinical Symptom of an Idiopathic Temporal Encephalocele in a 64 Year Old Man
}

\section{Krause-Titz $\mathrm{UR}^{* 1}$, Petridis $\mathrm{AK}^{* 2}$, Barth $\mathrm{H}^{1}$ and Mehdorn $\mathrm{HM}^{1}$}

${ }^{1}$ Department of Neurosurgery, University of Schleswig-Holstein, Kiel, Germany

${ }^{2}$ Department of Neurosurgery, Sana Clinics Duisburg, Germany

${ }^{*}$ Corresponding author: Krause-Titz UR and Petridis AK, Department of Neurosurgery, University Hospital Schleswig-Holstein Campus Kiel and Department of neurosurgery, Sana Clinics Duisburg, Germany, E-mail: ricklef@web.de; opticdisc@aol.com

Citation: Krause-Titz UR, Petridis AK, Barth H, Mehdorn HM (2015) Spontaneous CSF Rhinorrhea as Clinical Symptom of an Idiopathic Temporal Encephalocele in a 64 Year Old Man. J Case Rep Stud 3(3): 304. doi: 10.15744/2348-9820.3.304

Received Date: February 17, 2015 Accepted Date: June 09, 2015 Published Date: June 11, 2015

\section{Abstract}

A rare case of idiopathic temporomesial encephalocele in a 64 years old female is presented. The clinical symptoms of this adult patient were spontaneous rhinorrhea and headaches. A temporomesial encephalocele could be diagnosed and the cele was removed surgically in two operative procedures. In case of clinical symptoms like rhinorrhea a surgical removal of the encephalocele is recommended to prevent infections like meningitis.

Keywords: Encephalocele; Temporal lobe; Elderly; CSF rhinorrhea

\section{Introduction}

Idiopathic temporal encephaloceles are rare conditions with a reported incidence of approximately 1 in 35,000 people [1]. Encephaloceles were etiopathologically described since 1888 as a prolonghed persistence of the so-called Sternberg canal [2].

Newer anatomical and physiological findings combine arachnoid pits, pneumatisation of the lateral sphenoid sinus and an (partially) empty sella [3].

Therefore a classification of spontaneous lateral sphenoid cephaloceles into 2 subtypes have been proposed by their anatomical location: Type 1 with Herniation of the cele into a pneumatized sphenoid sinus often present with a CSF leakage and Type 2 which herniates into or through the greater wing of the sphenoid via e.g. a bony defect. In this group patients often present with seizures or headache and not as in our case with a CSF Leakage [4].

\section{Case presentation}

We present a rare case of an idiopathic temporomesial encephalocele in a 64 years old patient who complained about 3 weeks of headaches and rhinorrhea without any trauma in his history (Figure $1 \mathrm{~A}$ and $\mathrm{B}$ ).

The Ear Nose Throat (ENT) colleagues could not find a source of the rhinorrhea, but the patient has been treated with oral antibiotics because of a sinusitis.

After 1 week of persisting "water-like" secretion a computer tomography (CT) scan was performed with no pathological finding according to the outpatient colleagues. Indeed there has been a bony defect and finally after 3 weeks, a cranial magnetic resonance imaging (MRI) has been performed (Figure 1) and the patient was admitted to our department.

In the clinical neurological examination and lab analysis there were no signs of meningitis or other neurological deficits. The rhinorrhea could be provoked by leaning the patient's head forwardly. The CSF rhinorrhea was confirmed with a $\beta 2$-transferrin test.

We decided to surgically treat the encephalocele. In the surgical procedure we used a right pterional approach, removed the encephalocele and sealed the defect with a temporal muscle and fascia graft.

The CSF rhinorrhea did not occur again after surgery and the patient could be discharged without any complains on the $7^{\text {th }}$ postoperative day. The postoperative cranial CT scan showed no remnants of the cele and no CSF-leakage. Six months later the patient presented again in our outpatient clinics with a recurrence of CSF-rhinorrhea. We performed a cranial MRI as well as a high resolution skull base CT-scan and diagnosed the leakage of the used autologous dural graft (Figure 2A and B).

We decided to re-operate and used a fibrin coated collagen sponge as well as small bone fragment, which we fixed on the temporal bone as an abutment to stabilize the sealing (Figure $3 \mathrm{~A}$ and $\mathrm{B}$ ).

Afterwards the patient recovered well and could be dismissed 6 days after the second surgical procedure without any complains. In the period of the last 2 years she was not re-admitted. 


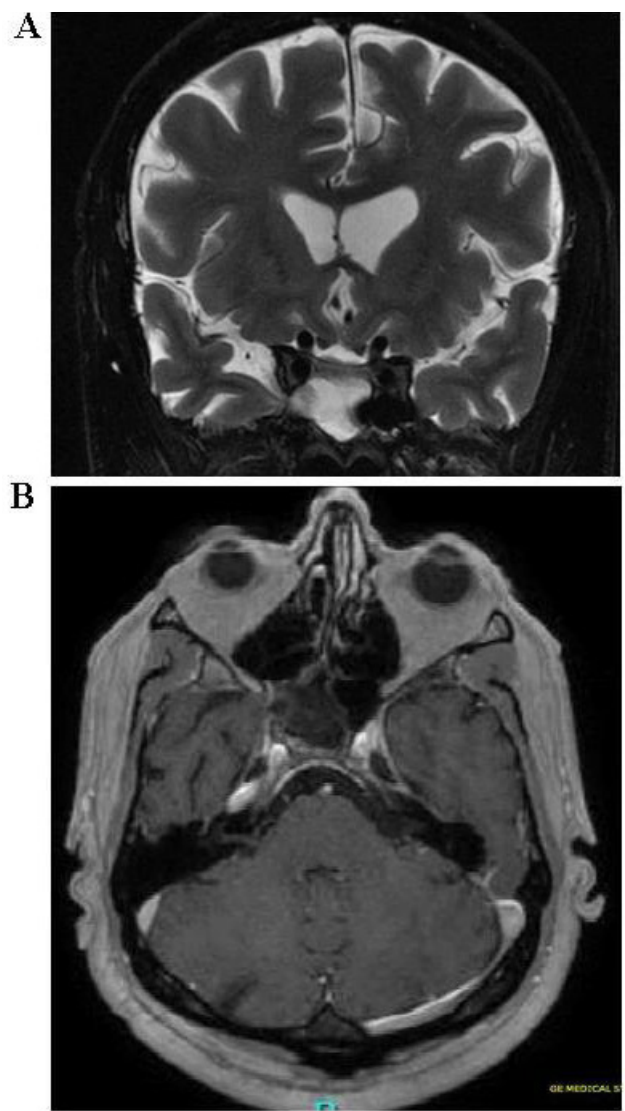

Figure 1: A) Preoperative MRI scan (coronal section T2-weihghted) B) T1 weighted axial section

A

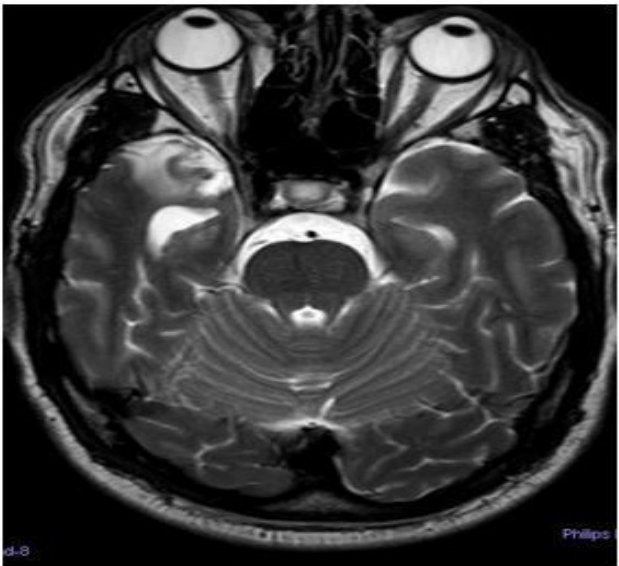

B

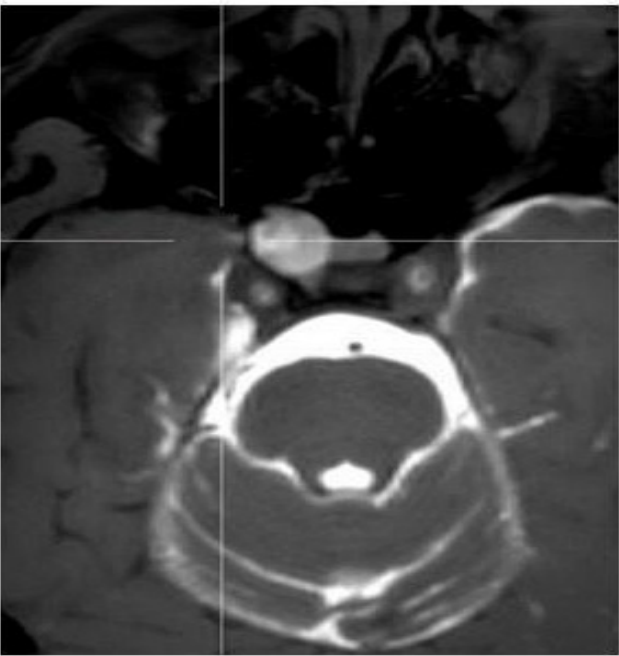

Figure 2: A) MRI. T2-weighted scan before 6 months after surgery showing a new leakage on the operated region $\mathbf{B}$ ) CSF leakage scan before $2^{\text {nd }}$ procedure 

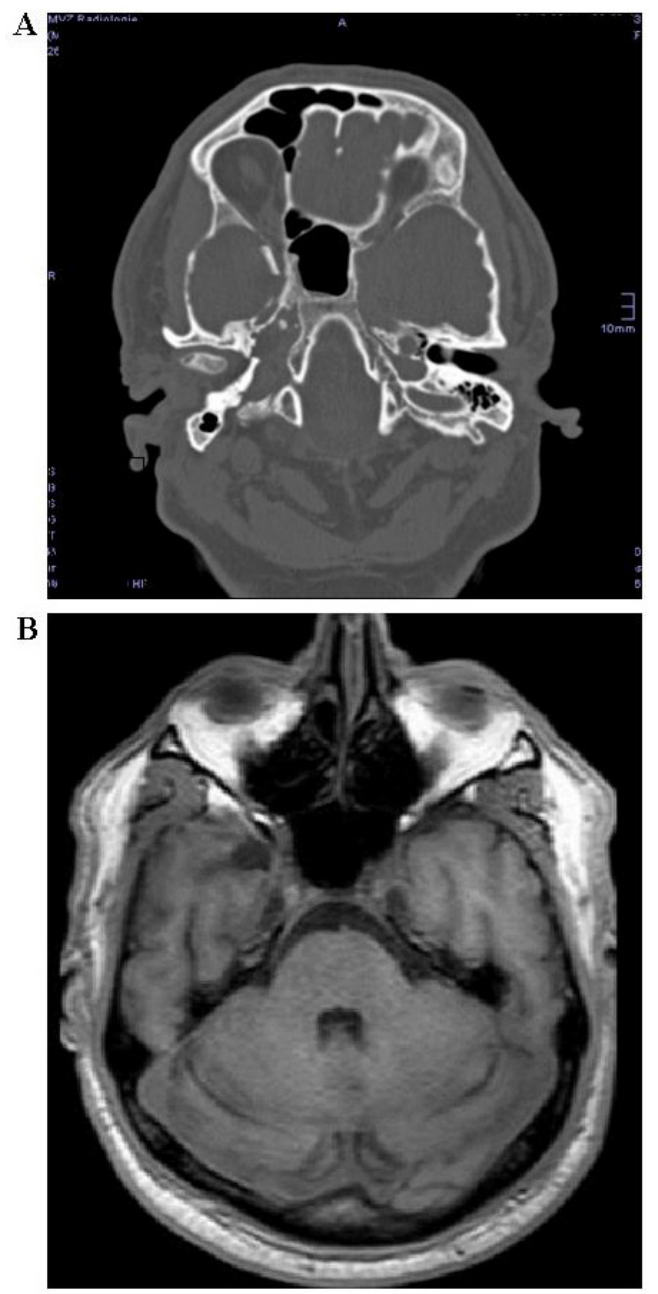

Figure 3: A) Postoperative CT scan after $2^{\text {nd }}$ procedure B) Postoperative MRI scan after $2^{\text {nd }}$ procedure (T1-weighted, axial section)

\section{Discussion}

There are a few cases of temporal encephaloceles described in literature [4-6].

The encephalocele of the present case is located anteromedial of the temporal lobe. A pneumatisation of the lateral sphenoid sinus is retrospectively visible on an MRI Scan before the surgical procedure, as well as a partial empty sella in the coronal MRI scan.

The difficulty in this case has been to localize the point of the CSF leakage, which finally has been solved via a high resolution skull base CT scan. Additionally the postulated intracranial hypertension or different CSF dynamics might be the reason of recurrence of the CSF-fistula.

CSF-rhinorrhea put the patient on a significantly higher risk for meningitis [7].

In cases of symptoms like CSF-rhinorrhea with an increased risk for meningitis, surgery should be performed after detailed high resolution CT scan and multiplanar MRI scan to avoid a second surgical procedure. Whether it should be performed endoscopically or microscopically depends on the expertise of the surgeon and on the anatomical localisation.

\section{References}

1. Wind JJ, Caputy AJ, Roberti F (2008) Spontaneous encephaloceles of the temporal lobe. Neurosurg Focus 25: E11.

2. Sternberg M (1890) Ein bisher nicht beschriebener Kanal im Keilbein des Menschen. Anat Anz 23: 784-6.

3. Baranano CF, Joel C, James NP, Bradford AW (2009) Sternberg's anal: fact or fiction? Am J Rhino Aller 23: 167-71.

4. Settecase F, Harnsberger HR, Michel MA, Chapman P, Glastonbury CM (2014) Spontaneous lateral sphenoid cephaloceles: anatomic factors contributing to pathogenesis and proposed classification. AJNR Am J Neuroradiol 35: 784-9.

5. Kamiya K, Mori H, Kunimatsu A, Kawai K, Usami K, et al. (2012) Two cases of spontaneous temporal encephalocele. J Neuroradiol 39: 360-3.

6. Wilkins RH, Radtke RA, Burger PC (1993) Spontaneous temporal encephalocele. Case Report. J Neurosurg 78: 492-8.

7. La Fata V, McLean N, Wise SK, DelGaudio JM, Hudgins PA (2008) CSF leaks: correlation of high-resolution CT and multiplanar reformations with intraoperative endoscopic findings. AJNR Am J Neuroradiol 29: 536-41. 


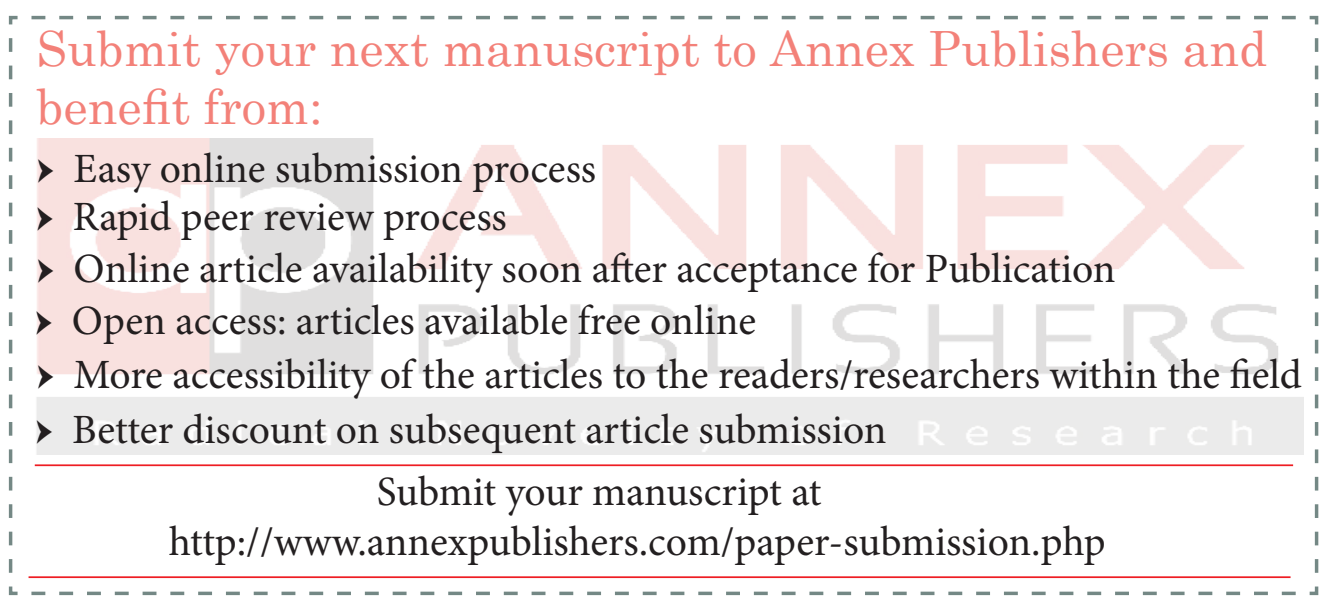

